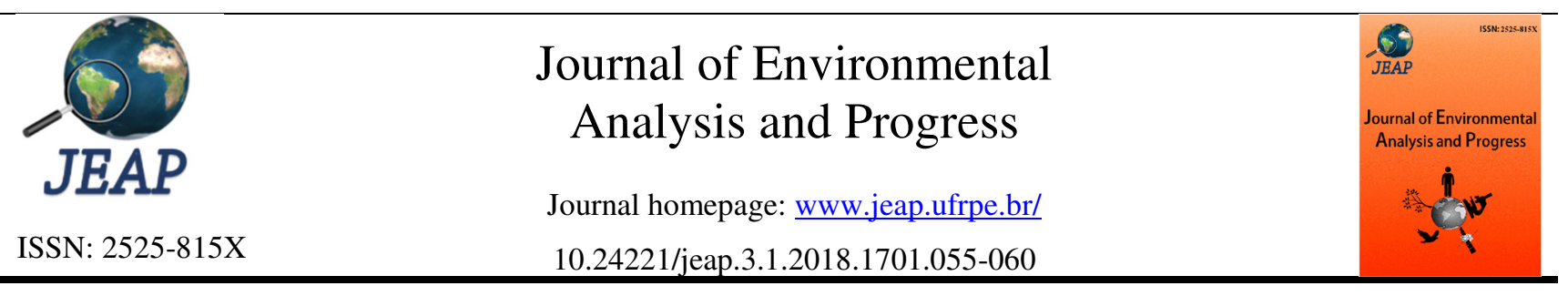

\title{
Potential production of bioplastics polyhydroxyalkanoates using residual glycerol
}

Priscilla Barbosa Sales de Albuquerque ${ }^{a}$, Katarynna Santos de Araújo ${ }^{a}$, Kelvin Augusto Azevedo da Silva $^{\mathrm{a}}$, Laureen Michelle Houllou ${ }^{\mathrm{a}}$, Gabriel Olivo Locatelli ${ }^{\mathrm{b}}$, Carolina Barbosa Malafaia ${ }^{\mathrm{a}}$

${ }^{a}$ Centro de Tecnologias Estratégicas do Nordeste-CETENE, Av. Prof. Luís Freire, n. 01, Cidade Universitária, Recife, Pernambuco, Brasil. CEP: 50740-540. E-mail: bio.malafaia@ gmail.com.

${ }^{\text {b }}$ Universidade Federal Rural de Pernambuco-UFRPE, Rede Nordeste de Biotecnologia-RENORBIO, Rua Manoel de Medeiros, SN, Dois Irmãos, Recife, Pernambuco, Brasil. CEP: 52171-900.

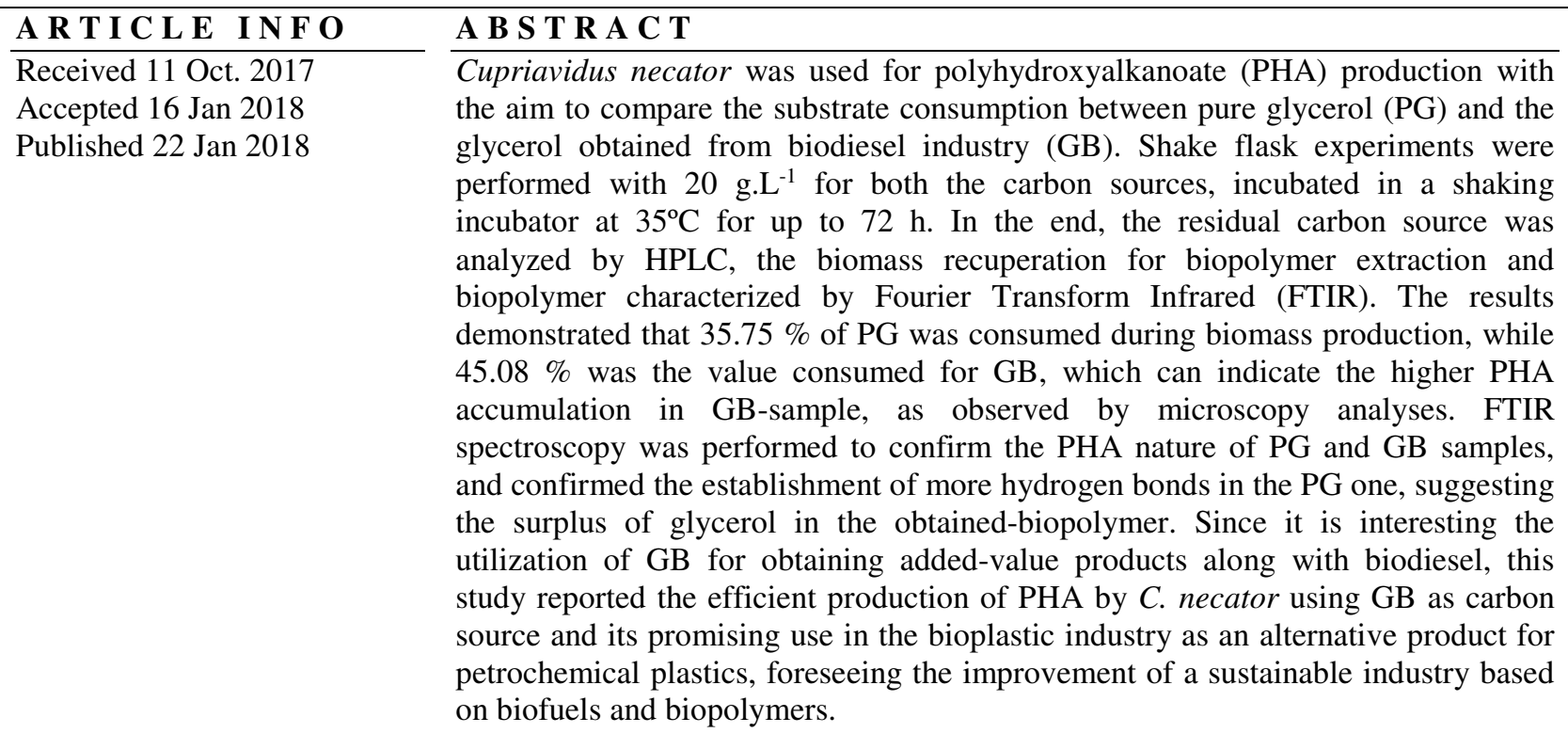

\section{Introduction}

Over the years, man has taken from nature both elements and products essential to his existence, trying to ensure comfort and a high quality of life. In the name of the well-being and development, the society has explored many raw materials and various products synthesized by living organisms present as structural constituents, being mostly of organic origin. Biopolymers are their representatives, presenting high molecular weight and classified according to the monomeric units used and the structure of the produced molecule; in addition, they can also be classified depending on their origin, including groups of proteins, polysaccharides, lipids/surfactants, polyphenols, and polyesters (Yadav et al., 2015). In this study, special attention is given to polyesters, a class of biopolymers formed by ester linkages between molecules of organic acids and alcohol.
Polyhydroxyalkanoates (PHAs) are naturally occurring aliphatic polyesters consisting of carbon, hydrogen, and oxygen (Du et al., 2012). They are accumulated by a wide variety of bacteria from intracellular reserve materials and produced by different substrates, including industrial byproducts, fats and oils, lignocellulosic raw materials, agricultural and household waste materials, sugars, wastewater, and glycerol (Witholt \& Kessler, 1999). PHAs are deposited in the cytoplasm of cells in the form of granules presenting the advantage of storing excess nutrients without affecting the physiological conditioning of the microorganism (Castilho, Mitchell \& Freire 2009). Poly(3hydroxybutyrate), or $\mathrm{P}(3 \mathrm{HB})$, the most known and studied PHA, was also the first one to be discovered. Cupriavidus necator is the most studied and most frequently used bacterium in the industrial obtainment of $\mathrm{P}(3 \mathrm{HB})$ due to its ability to accumulate an expressive amount of polymer at 
the end of the growth exponential step (Vandamme \& Coenye, 2004).

Plastic wastes are commonly found in urban centers but also accumulated in all environments where man is present. They are usually disposed very rapidly and considered severe damages when they return to the environment. Because of this behavior, there was an increase in the global awareness by minimizing the waste generated, in addition to the scientific community concern for technological alternatives to solve this problem. Alternatively, biopolymers are attracting special interest due to their inherent properties, which are similar to the ones of the conventional plastics (Albuquerque \& Malafaia, 2017).

There are several plastics derived from biopolymers and already commercially available, such as PHAs, polyglycolate (PGA), polylactates (PLA), and blends made from mechanical mixtures of different plastics. PHAs are recognized as the most well-known bioplastics because of their renewable resources and the characteristic to biodegrade under controlled conditions at the end of their use phase with zero toxic effects (Albuquerque \& Malafaia, 2017). In this way, there is a special interest for PHAs since the allure of biopolymers is also linked to the depletion of petrochemical reserves.

Although PHAs have been recognized as useful candidates to replace conventional petrochemical plastics, their use in a wide range of applications is still limited due to their high production price. Alternative solutions have been proposed from the development of production processes based on waste carbon sources or industrial by-products instead of noble ones, since around $40 \%$ of production costs refer to the raw material used as carbon source (Campanari et al., 2017; Lee et al., 2015; Martinez et al., 2015). Currently, the biodiesel production generates about $10 \%(\mathrm{w} / \mathrm{w})$ glycerol as the main byproduct. Since this is a high-value chemical, the surplus of glycerol (residual glycerol) obtained by biodiesel production presents opportunities for new applications (Figueiredo et al., 2014).

As the increase of the demand for biodiesel is desirable to promote sustainable processes for utilizing residual glycerol, this study aimed at the production of PHA by $C$. necator using residual glycerol as a carbon source and the characterization of the obtained biopolymer.

\section{Material and Methods}

Chloroform PA ACS was obtained from Qhemis (Brazil), pure ethanol from Sigma Aldrich (Brazil), and acetone from Vetec Fine Chemicals
Ltda. (Brazil). Residual glycerol (called GB in this study) used as a substrate in PHA production was supplied by Usina Experimental Piloto Caetés of the Centro de Tecnologias Estratégicas do Nordeste (CETENE), Pernambuco, generated with a yield of $99.5 \%$ during the production of biodiesel. Pure glycerol (PG) was obtained from Alphatec (Brazil), and bacterial strain of C. necator (DSMZ 545) was obtained from the culture collection of the Department of Antibiotics of the Federal University of Pernambuco (UFPEDA 0604).

\section{Biomass production}

The strain was cultured on nutrient agar (5 g. $\mathrm{L}^{-1}$ beef peptone, 3 g.L. $\mathrm{L}^{-1}$ beef extract, and 18 g. $\mathrm{L}^{-1}$ agar) for $24 \mathrm{~h}$ at $35^{\circ} \mathrm{C}$. A pre-inoculum was cultured for $24 \mathrm{~h}$ at $35^{\circ} \mathrm{C}$ and $250 \mathrm{rpm}$ in nutrient broth (5 g.L $\mathrm{L}^{-1}$ beef peptone and 3 g.L $\mathrm{L}^{-1}$ beef extract). The inoculum was prepared at $10 \%(\mathrm{v} / \mathrm{v})$ concentration in mineral salts medium (Table 1) containing 20 g.L $\mathrm{L}^{-1}$ of the pure glycerol (PG) or the same concentration of the residual glycerol obtained from biodiesel industry (GB) as carbon sources. The medium with carbon sources was autoclaved for $20 \mathrm{~min}$ at $121^{\circ} \mathrm{C}$. After that, the flasks containing inoculum, mineral salts medium and $\mathrm{PG}$ or GB were incubated at $35^{\circ} \mathrm{C}$ for up to 72 h.

PHA-producing bacteria were stained with Sudan Black by the methodology described by (Schlegel, Lafferty \& Krauss, 1970) with some modifications. Briefly, the biomass was flamefixed on a glass slide and covered with $0.3 \%$ Sudan Black (w/v) dissolved in 70\% ethanol (v/v) for $15 \mathrm{~min}$, then decolorized with xylene for $20 \mathrm{~s}$. After that, the material was covered with $10 \%$ safranin ( $\mathrm{v} / \mathrm{v})$ dissolved in $95 \%$ ethanol (v/v) for 5 sec. and washed with $70 \%$ ethanol (v/v). Optical analysis of the slides was carried out using a Leica DM500 Binocular Microscope with LAS EZ ICC 50 HD software (100× Magnification).

GB and PG quantifications were performed by HPLC apparatus (HPLC Alliance e2695, Waters, UK) linked to a refractive index detector (Water, 2414), equipped with a Rezex RHM monosaccharide H+ $(8 \%)$ column (Phenomenex®). Samples of $20 \mu \mathrm{L}$ were injected and eluted with $100 \%$ water at a flow rate of 0.6 mL.min-1. The column was kept at $35^{\circ} \mathrm{C}$.

\section{Biopolymer extraction}

The extraction method was performed according to the methodology described by Ramsay et al. (1994), which was based on cell lysis and washing steps with different solvents to remove cell debris, followed by solubilization of 
the biopolymer in chloroform, and finally, the recovering by precipitation in ice-cold ethanol. The extraction method used the same centrifugation conditions at all steps, being $4000 \mathrm{x}$ $\mathrm{g}, 10^{\circ} \mathrm{C}, 20 \mathrm{~min}$ and half of the initial volume of culture medium for all the solvents used in resuspension. Briefly, the bacterial suspension was centrifuged, the supernatant discarded, and the obtained precipitate was resuspended in $0.2 \mathrm{~N}$ $\mathrm{NaOH}$. Then, the material was stirred at $200 \mathrm{rpm}$, $30^{\circ} \mathrm{C}$ for $2 \mathrm{~h}$, centrifuged again, discarding the supernatant and resuspending the precipitate in ethanol. The material was submitted to new centrifugation, being the supernatant discarded and the precipitate resuspended in acetone. After discarding the acetone-supernatant, the precipitate was resuspended in chloroform (20:1) and stirred at $200 \mathrm{rpm}$ for $24 \mathrm{~h}$. The same volume of distilled water was added and stirred at $200 \mathrm{rpm}$ for $24 \mathrm{~h}$. After this period, one can observe a system composed of three phases, being the first one the aqueous phase (polar), the second composed of impurities and the third the organic phase (apolar). The system was placed in a separating funnel, and the third phase (composed of chloroform) was dripped in an equal volume of ice-cold ethanol (kept in an ice bath). The precipitate was placed in Petri dishes, dried until complete evaporation and finally called PHA. All the experiments for obtaining PHA was done in triplicate.

\section{Characterization of the PHA obtained by Cupriavidus necator}

After drying, PHA was characterized according to the following experiments: PHA contents and its components were determined by gas chromatography (GC-7890A Agilent Technologies, EUA). 20-30 mg of obtained-PHA were dissolved in $1 \mathrm{~mL}$ of chloroform PA, filtered in $0.22 \mu \mathrm{m}$, and submitted to analysis in a gas chromatography equipped with a DB-5MS capillary column ( $30 \mathrm{~m}$ by $0.25 \mathrm{~mm}$ ) and a flame ionization detector. The gas chromatographer was operated with the following conditions: the temperature of the injector and detector was $250^{\circ} \mathrm{C}$. A temperature program was adopted for efficient separation of the esters $\left(60^{\circ} \mathrm{C}\right.$ for $2 \mathrm{~min}$, increased $25^{\circ} \mathrm{C} \cdot \mathrm{min}^{-1}$ to $180^{\circ} \mathrm{C}$ for $8 \mathrm{~min}$ ). Under these conditions, the retention times (in $\mathrm{min}$ ) of PHA major component was 12.52. The biopolymer was also characterized by Fourier Transform Infrared (FTIR) spectroscopy on a VERTEX 70 (Bruker Optics, USA) spectrometer under dry air at room temperature $\left(25^{\circ} \mathrm{C}\right)$. The spectra of the biopolymers obtained from crude and residual glycerol were scanned between 4000 and $500 \mathrm{~cm}^{-1}$ with $4 \mathrm{~cm}^{-1}$ of resolution.
Table 1. Mineral salts medium composition for Cupriavidus necator cultivation.

\begin{tabular}{|c|c|}
\hline Microelement solution & {$\left[\right.$ g. $\left.\mathbf{L}^{-1}\right]$} \\
\hline $\mathrm{H}_{3} \mathrm{BO}_{3}$ & 0,3 \\
\hline $\mathrm{CoCl}_{2} \cdot 6 \mathrm{H}_{2} \mathrm{O}$ & 0,2 \\
\hline $\mathrm{ZnSO}_{4} \cdot 7 \mathrm{H}_{2} \mathrm{O}$ & 0,1 \\
\hline $\mathrm{MnCl}_{2} .4 \mathrm{H}_{2} \mathrm{O}$ & 0,03 \\
\hline $\mathrm{Na}_{2} \mathrm{MoO}_{4} \cdot 2 \mathrm{H}_{2} \mathrm{O}$ & 0,03 \\
\hline $\mathrm{CuSO}_{4} .5 \mathrm{H}_{2} \mathrm{O}$ & 0,01 \\
\hline Other reagents & [g. $\left.\mathrm{L}^{-1}\right]$ \\
\hline $\mathrm{CH}_{2} \mathrm{CO}_{2} \mathrm{H}$ & $105 \mathrm{uL}$ \\
\hline$\left(\mathrm{NH}_{4}\right)_{2} \mathrm{Fe}\left(\mathrm{SO}_{4}\right)_{2} \cdot 6 \mathrm{H}_{2} \mathrm{O}$ & 0,06 \\
\hline $\mathrm{Mg}_{2} \mathrm{SO}_{4} \cdot 7 \mathrm{H}_{2} \mathrm{O}$ & 0,5 \\
\hline $\mathrm{CaCl}_{2} \cdot 2 \mathrm{H}_{2} \mathrm{O}$ & 0,01 \\
\hline $\mathrm{Na}_{2} \mathrm{HPO}_{4} .12 \mathrm{H}_{2} \mathrm{O}$ & 8,95 \\
\hline $\mathrm{KH}_{2} \mathrm{PO}_{4}$ & 1,5 \\
\hline$\left(\mathrm{NH}_{4}\right) 2 \mathrm{SO}_{4}$ & 5 \\
\hline $\mathrm{C}_{6} \mathrm{H}_{8} \mathrm{O}_{7}$ & $36 \mathrm{uL}$ \\
\hline
\end{tabular}

${ }^{*} \mathrm{pH}$ adjusted to 7 .

\section{Results}

The intracellular presence of PHAs in both PG and GB cultures by staining with Sudan Black can be observed in Figure 1. Through optical microscopy, it is possible to observe a different behavior for both cultures, being GBcells larger than the PG-ones, with an altered shape due to the higher accumulation of PHAs.

HPLC analysis demonstrated that $35.75 \%$ of PG was consumed during biomass production, while $45.08 \%$ was the value consumed for GB. By microscopy analyses, it can be observed the intracellular accumulation of PHAs in GB-cells, which is higher than the PG culture. Therefore, the higher amount of GB consumed during the process can indicate a higher PHA accumulation when compared to PG culture.

FTIR is a valuable technique for studying polymers, estimating chemical interactions and possible modifications in their structure (Albuquerque et al., 2017). Figure 2 shows typical bands and signals for PHAs. However distinct differences were observed for $\mathrm{GB}$ and $\mathrm{PG}$ obtained-biopolymers. The spectra of both samples showed a peak attributed to the stretching vibration of the carbonyl group $(\mathrm{C}=\mathrm{O})$ in esters (around $1715 \mathrm{~cm}^{-1}$ ) (Figueiredo et al., 2014; Rodríguez-Contreras et al., 2015) and peaks in the region between 2800 and $3000 \mathrm{~cm}^{-1}$, attributed to $\mathrm{CH}$ stretching vibration. GB and PG samples also presented the broadband ranging between 3100 and $3500 \mathrm{~cm}^{-1}$, attributed to $\mathrm{OH}$ stretching vibration (Yuen et al., 2009); also, it is possible to note that the vibration was more intense for PG. 
The scientific literature reports the region near to $1000 \mathrm{~cm}^{-1}$ correspondent to the stretching

vibration of $\mathrm{CO}$ in $\mathrm{C}-\mathrm{O}-\mathrm{C}$ bonds, and it appears in both obtained-biopolymers.

Figure 1. Intracellular accumulation of PHAs in culture with PG (A) and GB (B).

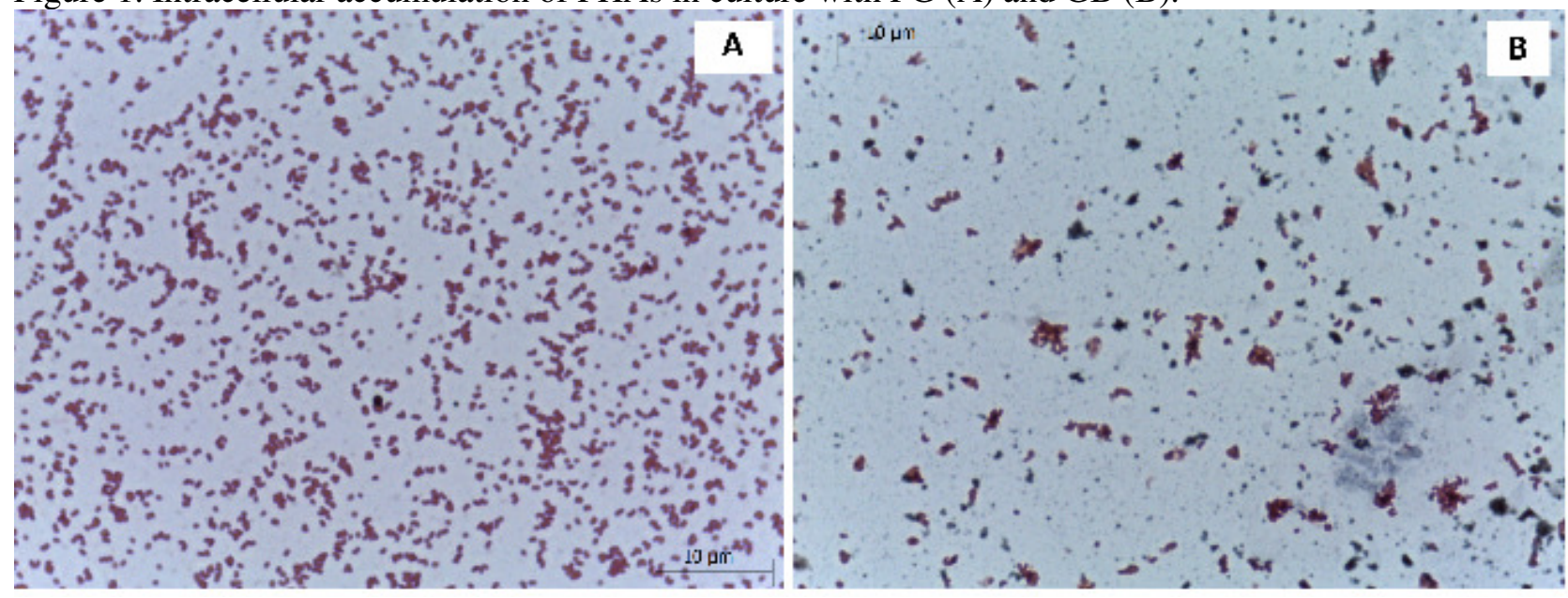

Figure 2. Fourier Transform Infrared (FTIR) spectra of the PHAs obtained by GB and PG.

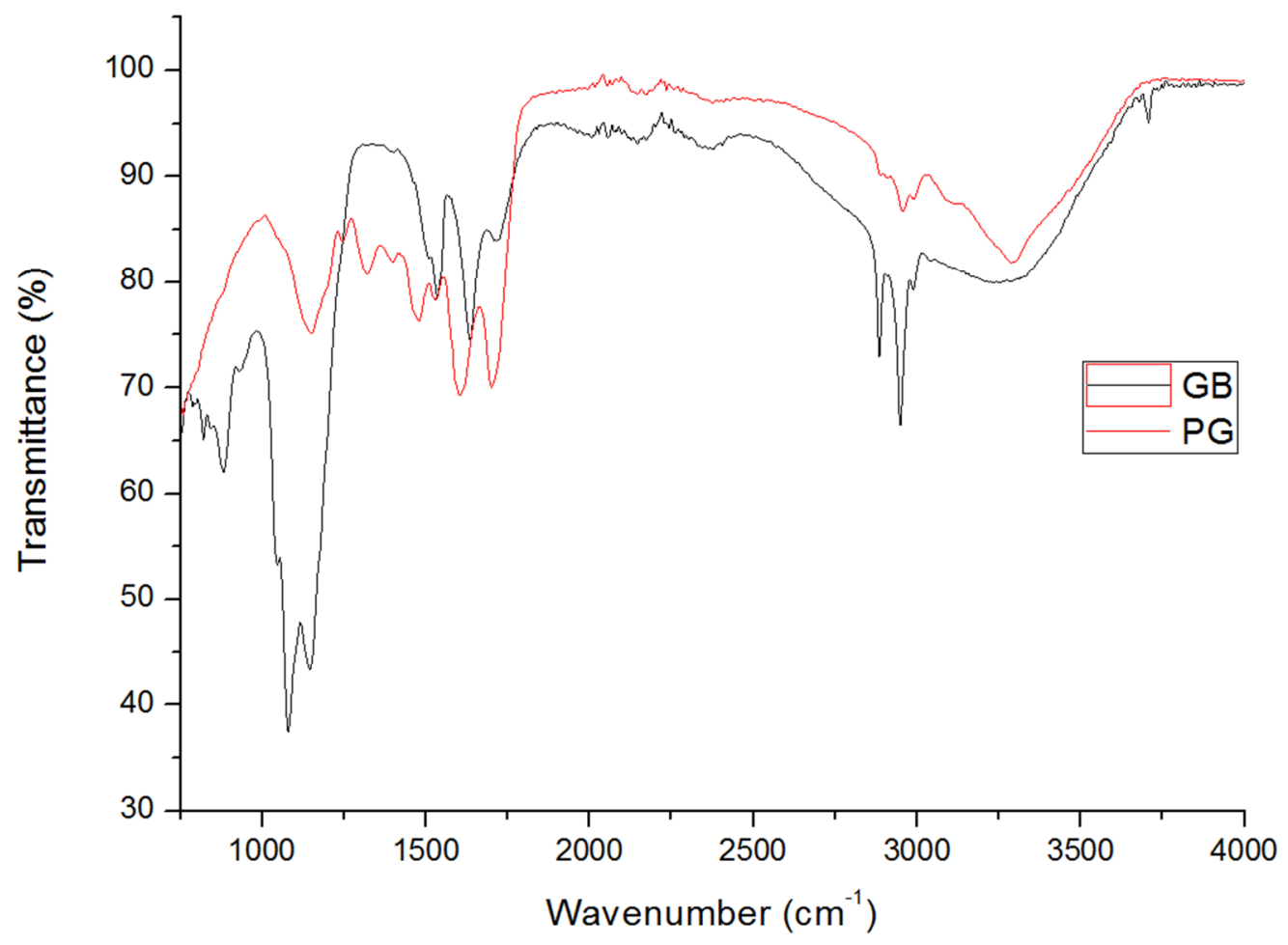

\section{Discussion}

There are many PHAs producer's microorganisms, and C. necator is one of the most important due to its favorable conditions for industrial production, accumulating around $80 \%$ of its dry mass in biopolymer. This bacterium requires the limitation of an essential nutrient (nitrogen, phosphorus, magnesium, sulfur or oxygen) for the synthesis of PHA from an excess of carbon source (Albuquerque \& Malafaia, 2017; Khanna \& Srivastava, 2005).
Using glycerol as a substrate, $C$. necator can produce biomass and PHA by fermentation in flasks under different conditions of time and temperature; in this case, 72 hours and $35^{\circ} \mathrm{C}$ were chosen based on preliminary analyses (results not shown). Possibly, if the cultivation had been extended for a more extended period, the residual concentration of glycerol would decrease, by continuing the biopolymer accumulation. Nevertheless, it is important to mention the aim of using GB, adding value to this biodiesel industry co-product and enabling the reduction of 
production costs of the biopolymer. Also, it is possible to consider the intracellular accumulation of PHA and the extraction process using GB as efficient in obtaining the biopolymer by lysis cell. Comparing the results presented by PG cultures at the same conditions, one can consider GB as an active substrate for the biological production of value-added products with potential industrial uses. This behavior could be observed in other published studies. For instance, a new bacterial strain isolated from Atlantic rainforest in Brazil was tested by de Paula et al. (2017) for PHA production, utilizing crude glycerol from biodiesel industry. These authors verified that PHA production was higher in residual glycerol than the pure one at all studied concentrations, which is in agreement with the results obtained in this study. Also, studying with residual glycerol generated by the production of biodiesel from soybean oil and methanol, Figueiredo et al. (2014) used different conditions of time and temperature for $C$. necator fermentation. Even considering the same conditions of this study, our results showed better yield when compared to their values $(22.22 \%)$.

The FTIR results in mixed compounds commonly lead to modifications in characteristic spectral peaks. In general, both GB and PG obtained-biopolymers presented a broad band between the region $3100-3500 \mathrm{~cm}^{-1}$, representing $\mathrm{OH}$ stretching vibration formed by hydroxyl groups between the obtained-biopolymers and water involved in hydrogen bonding. However, it is evident the lower intensity for GB peak, which can be associated with hydroxyl bonds that decrease when GB is used during $C$. necator fermentation. Glycerol, due to its hydrophilic nature, can retain higher quantities of water; in this case, the surplus of PG favored the adsorption of water molecules, which is mainly attributed to its predisposition to form hydrogen bonds (Cerqueira et al., 2012). The increase in the area of the peak around $3285 \mathrm{~cm}^{-1}$ confirmed the results observed for HPLC analysis about the surplus of PG, which was higher than GB during the entire process.

There is also a great difference observed in the region $2800-3000 \mathrm{~cm}^{-1}$, i.e., the decrease in $\mathrm{GB}^{\prime}$ area of the bands close to those at $2950 \mathrm{~cm}^{-1}$ that correspond to the $\mathrm{CH}$ stretching vibration. The surplus of glycerol in PG obtainedbiopolymer leads to higher numbers of $\mathrm{OH}$ bonds and consequently higher band areas, also resulting in the decrease of the areas that correspond to the $\mathrm{CH}$ bonds. Also, different amounts of glycerol between GB and PG obtained-biopolymers leads to a shift of the peak near to $1140 \mathrm{~cm}^{-1}$, associated to the tension of anti-symmetric vibration of the ester group (Rodríguez-Contreras et al., 2015).

\section{Conclusion}

The use of renewable resources for the production of bioplastics is often associated with reducing the number of plastics from the petrochemical industry. The use of PHAs as a substitute for the conventional plastics depends on the ability to produce biopolymers at competitive costs. It is interesting the utilization of GB for obtaining added-value products along with biodiesel; this study reported an efficient production of PHAs by $C$. necator using GB as a carbon source and lysis cell as extraction process. The obtained biopolymer could be considered a promising alternative in the bioplastic industry, foreseeing the improvement of a sustainable industry based on biofuels and biopolymers.

\section{Acknowledgements}

Priscilla B. S. Albuquerque expresses gratitude to the Fundação de Amparo à Ciência e Tecnologia do Estado de Pernambuco (FACEPE), for funding the study by FACEPE 02/17 of the agreement between FACEPE and Centro de Tecnologias Estratégicas do Nordeste (CETENE). Authors express gratitude to Conselho Nacional de Desenvolvimento Científico e Tecnológico (CNPq) for financial support and to CETENE for structural support.

\section{References}

ALBUQUERQUE, P. B. S.; MALAFAIA, C. B. 2017. Perspectives on the production, structural characteristics and potential applications of bioplastics derived from polyhydroxyalkanoates. Int. J. Biol. Macromol., v. 3, p. 0-23.

ALBUQUERQUE, P.B.S.; CERQUEIRA, M.A.; VICENTE, A.A.; TEIXEIRA, J.A.; CARNEIRODA-CUNHA, M.G. 2017. Immobilization of bioactive compounds in Cassia grandis galactomannan-based films: influence on physicochemical properties. Int. J. Biol. Macromol., v. 96, p. 727-35.

CAMPANARI, S.; AUGELLETTI, F.; ROSSETTI, S.; SCIUBBA, F.; VILLANO, M.; MAJONE, M. 2017. Enhancing a multi-stage process for olive oil mill wastewater valorization towards polyhydroxyalkanoates and biogas production. Chem. Eng. J., v. 317, p. 280-289.

CASTILHO, L. R.; MITCHELL, D. A.; FREIRE, D. M. G. 2009. Production of polyhydroxyalkanoates (PHAS) from waste 
materials and by-products by submerged and solid-state fermentation. Bioresour. Technol., v. 100, n. 23, p. 5996-6009.

CERQUEIRA, M. A.; SOUZA, B. W. S.; TEIXEIRA, J. A.; VICENTE, A. A. 2012. Effect of glycerol and corn oil on physicochemical properties of polysaccharide films - a comparative study. Food Hydrocoll., v. 27, n. 1, p. 175-184.

DU, C.; SABIROVA, J.; SOETAERT, W.; LIN, S. K. C. 2012. Polyhydroxyalkanoates production from low-cost sustainable raw materials. Curr. Chem. Biol., v. 6, n. 1, p. 14-25.

FIGUEIREDO, T. V. B.; CAMPOS, M. I.; SOUSA, L. S.; SILVA, J. R.; DRUZIAN, J. I. 2014. Produção e caracterização de polihidroxialcanoatos obtidos por fermentação da glicerina bruta residual do biodiesel. Quim. Nova, v. 37 , n. 7 , p. 1111-1117.

KHANNA, S.; SRIVASTAVA, A. K. 2005. recent advances in microbial polyhydroxyalkanoates. Process Biochem., v. 40, p. 607-619.

LEE, W. S.; CHUA, A. S. M.; YEOH, H. K.; NITTAMI, T.; NGOH, G. C. 2015. Strategy for the biotransformation of fermented palm oil mill effluent into biodegradable polyhydroxyalkanoates by activated sludge. Chem. Eng. J., v. 269, p. 288-297.

MARTINEZ, G.A.; BERTIN, L.; SCOMA, A.; REBECCHI, S.; BRAUNEGG, G.; FAVA, F. 2015. Production of polyhydroxyalkanoates from dephenolised and fermented olive mill wastewaters by employing a pure culture of Cupriavidus necator. Biochem. Eng. J., v. 97, p. 92-100.

DE PAULA, F. C.; KAKAZU, S.; DE PAULA, C. B. C.; GOMEZ, J. G. C.; CONTIERO, J. 2017. Polyhydroxyalkanoate production from crude glycerol by newly isolated Pandoraea sp. J. King Saud Univ. Sci., v. 29, n. 2, p. 166-173.

RAMSAY, J. A.; BERGER, E.; VOYER, R.; CHAVARIE, C.; RAMSAY, B. A. 1994. Extraction of poly-3-hydroxybutyrate using chlorinated solvents. Biotechnol. Tech., v. 8, n. 8, p. 589-94.

RODRÍGUEZ-CONTRERAS, A.; KOLLER, M.; DIAS, M. M. S.; CALAFELL-MONFORTE, M.; BRAUNEGG, G.; MARQUÉS-CALVO, M. S. 2015. Influence of glycerol on poly(3hydroxybutyrate) production by Cupriavidus necator and Burkholderia sacchari. Biochem. Eng. J., v. 94, p. 50-57.

SCHLEGEL, H. G.; LAFFERTY, R.; KRAUSS, I. 1970. The isolation of mutants not accumulating poly- $\beta$-hydroxybutyric acid. Arch. Mikrobiol., v. 71, p. 283-294.

VANDAMME, P.; COENYE, T. 2004. Taxonomy of the genus cupriavidus: a tale of lost and found. Int. J. Syst. Evol. Microbiol., v. 54, n. 6, p. 2285-2289.

WITHOLT, B.; KESSLER, B. 1999. Reviewperspectives of medium chain length poly(hydroxyalkanoates), a versatile set of bacterial bioplastics. Curr. Opin. Biotechnol., v. 10 , p. $279-85$.

YADAV, M. P.; HICKS, K. B.; JOHNSTON, D. B.; HOTCHKISS JR., A. T.; CHAU, H. K.; HANAH, K. 2015. Production of bio-based fiber gums from the waste streams resulting from the commercial processing of corn bran and oat hulls. Food Hydrocoll., v. 53, p. 125-33.

YUEN, S.-N.; CHOI, S.-M.; PHILLIPS, D. L.; MA, C.-Y. 2009. Raman and FTIR spectroscopic study of carboxymethylated non-starch polysaccharides. Food Chemi., v. 114, n. 3, p. 1091-98. 